\title{
One new species of the Clubiona trivialis-group (Araneae: Clubionidae) from Hebei Province, China
}

\author{
Xiaoyu Dong \& Feng Zhang* \\ The Key Laboratory of Invertebrate Systematics and Application, College of Life Sciences, \\ Hebei University, Baoding, Hebei 071002, P. R. China \\ *Corresponding author. E-mail: dudu06042001@163.com
}

\begin{abstract}
The present paper describes one new Clubiona trivialis-group species collected from Baishi Mountain, Hebei Province of China: Clubiona hooda sp. nov. ( $\left({ }^{\top}{ }^{7}\right)$. Illustrations and photographs of somatic and genitalic morphology are provided.
\end{abstract}

Key words - spider, taxonomy, northern China

\section{Introduction}

The genus Clubiona Latreille 1804 is the largest genus of the sac spider family Clubionidae. It currently includes 473 species with a nearly cosmopolitan distribution, excluding South America (World Spider Catalog 2015), and of which 105 species have been reported from China ( $\mathrm{Li} \&$ Wang 2015). Due to the high species diversity of the genus, many authors have suggested subdivisions of the genus into species groups, such as Simon (1932) for the French species, Lohmander (1944) for Swedish species, Wiehle (1965) for German species, Wunderlich (2011) for European species, Edwards (1958) for the North American species, Dondale \& Redner (1982) for Canadian and Alaskan species, Mikhailov $(1995,2012)$ for Holarctic species, and Deeleman-Reinhold (2001) for southeast Asian species.

Clubiona trivialis-group was formally named by Dondale \& Redner (1976), though in fact it was first recognized by Edwards (1958) as his group I, division A, and then Mikhailov (1995) restricted the species group with 19 Holarctic species. The species of trivialis-group can be distinguished by: the male retrolateral tibial apophysis not branched, wide, flat or almost flat, weakly angled or dentate, rarely attenuating; the female simple structure of circular or ovoid spermathecae combined with copulatory openings brought close together or fused into a single groove, and copulatory ducts straight or almost straight (Mikhailov 1995).

So far, there are at least 11 species of Clubiona trivialisgroup recorded in China (Li \& Wang 2015): C. asrevida Ono 1992, C. baimaensis Song \& Zhu 1991, C. diversa O. Pickard-Cambridge 1862, C. duoconcava Zhang \& Hu 1991, C. hedini Schenkel 1936, C. insulana Ono 1989, C. moesta Banks 1896, C. rostrata Paik 1985, C. subrostrata Zhang \& Hu 1991, C. trivialis C. L. Koch 1843, C. yangmingensis Hayashi \& Yoshida 1993.

While examining the spider specimens collected from Baishi Mountain, Hebei Province, China, we found a certain species of Clubiona trivialis-group. After careful examination of the specimens, we concluded that they are belonging to a new species, which is described here.

\section{Material and methods}

All measurements are given in millimetres. Leg measurements are shown as: total length (femur, patella, tibia, metatarsus, tarsus). Body length is the sum of the carapace and abdomen lengths, regardless of the pedicel. Epigynes were removed and cleared in a warm solution of $10 \%$ potassium hydroxide, transferred to alcohol and temporarily mounted for illustration. All specimens are preserved in $75 \%$ alcohol and were examined, illustrated and measured with a Leica M205A stereomicroscope equipped with an Abbe drawing device. Photographs were captured using a Leica M205A stereomicroscope equipped with a DFC550 CCD. The specimens are deposited in the Museum of Hebei University, Baoding, China (MHBU).

The following abbreviations are used in the text: AER anterior eye row; ALE - anterior lateral eyes; AME - anterior median eyes; EPA - embolar part apophysis; MOA median ocular area; PER - posterior eye row; PLE - posterior lateral eyes; PME - posterior median eyes; RTA retrolateral tibial apophysis.

\section{Taxonomy}

Clubiona Latreille 1804

Clubiona hooda sp. nov. Figs. 1-12

Type material. Holotype $\delta^{\lambda}$, China: Hebei Province, 


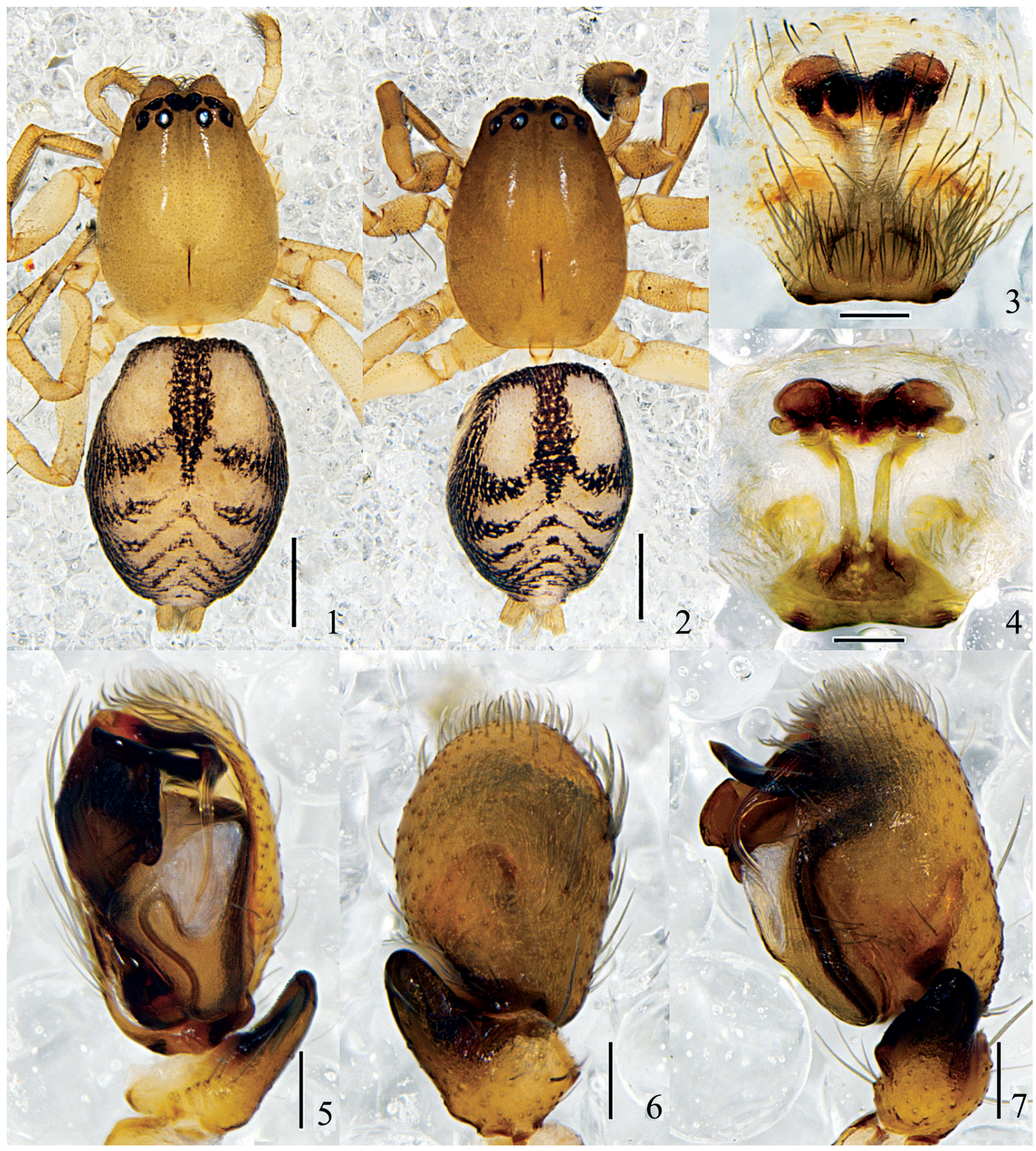

Figs. 1-7. Clubiona hooda sp. nov. 1, female habitus, dorsal view; 2, male habitus, dorsal view; 3, epigyne, ventral view; 4, vulva, dorsal view; 5 , left male palp, ventral view; 6 , same, dorsal view, showing tibial apophysis; 7 , same, retrolateral view. Scales $=0.5 \mathrm{~mm}(1-2) ; 0.1$ $\mathrm{mm}\left(3^{-7}\right)$.

Laiyuan County, Baishi Mountain $\left(39^{\circ} 24.093^{\prime} \mathrm{N}\right.$, $114^{\circ} 66.288^{\prime}$ E), $1325 \mathrm{~m}$ a.s.1., 19 August 2014, leg. Xiaoyu Dong. Paratypes: 2 우, same data as holotype.

Etymology. The specific name is a noun in apposition, and is arbitrary combination of letters which is associated by the epigyne with a pair of hoods.

Diagnosis. Among the species of the trivialis-group, the male of the new species resembles $C$. duoconcava Zhang \& $\mathrm{Hu}$ 1991, both with wide, short RTA, but can be distinguished from the latter by: (1) the tegulum distinctly lower than the base of embolus, whereas tegulum as high as the base of embolus in C. duoconcava; (2) the embolar part wider than that of the latter, and the embolus longer than that of the latter; (3) the EPA slender and curved to the 

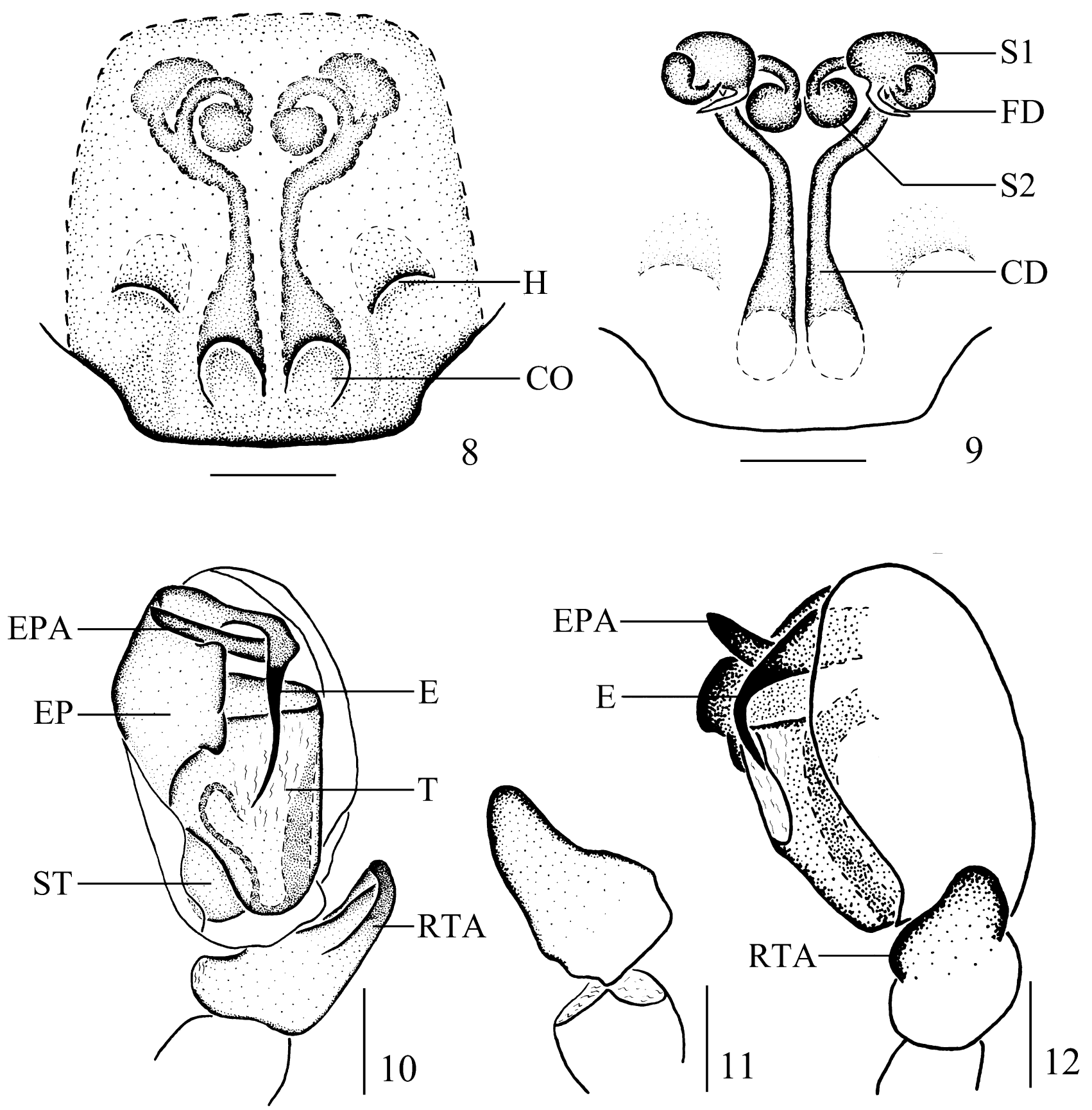

Figs. 8-12. Clubiona hooda sp. nov. 8, epigyne, ventral view; 9, vulva, dorsal view; 10, left male palp, ventral view; 11, tibia of left male palp, dorsal view; 12 , left male palp, retrolateral view. Scales $=0.25 \mathrm{~mm}$. Abbreviations: $\mathrm{CD}$ - copulatory duct; CO - copulatory opening; E - embolus; EP - embolar part; EPA - embolar part apophysis; FD - fertilization duct; H - hood; RTA - retrolateral tibial apophysis; S1 - primary spermatheca; S2 - secondary spermatheca; ST - subtegulum; T - tegulum.

prolateral side, whereas EPA triangular and pointed to the retrolateral side in the latter. The female is similar to $C$. baimaensis Song \& Zhu 1991 in having big copulatory openings which far apart from the spermathecae, but can be distinguished from the latter by: (1) the posterior part of epigyne with a pair of hoods, whereas without hood in the latter; (2) the posterior edge of epigyne wider than that of the latter; (3) the copulatory openings close to each other but not fused into a single groove as that of in the latter; (4) the copulatory ducts shorter than those of the latter.

Description. Male. Holotype (Fig. 2): body length 3.63; carapace length 1.76, width 1.33; abdomen length 1.87, width 1.36. Carapace oval and yellow brown, almost without lateral invaginations behind the cephalic part. Median furrow brown, longitudinal and long. From dorsal view, AER slightly recurved, PER almost straight. Eye sizes and interdistances: AME 0.08, ALE 0.11, PME 0.09, PLE 0.11; AME-AME 0.12, AME-ALE 0.05, PME-PME 0.24, PME- 
PLE 0.14. MOA length 0.25 , front width 0.31 , back width 0.42. Clypeus height 0.04 . Chelicerae yellow brown, promargin of fang furrow with five teeth, retromargin with four teeth. Endites yellow, longer than wide. Labium yellow brown, longer than wide. Abdomen oval, dorsally light grey; anterior half without a scutum, with a longitudinal black stripe; posterior half with several distinct black chevron-like markings; lateral sides black; cardiac pattern yellow brown. Spinnerets and legs pale yellow brown. Tibiae I-II each with two pairs of ventral spines, metatarsi I-II each with one ventral spines. Measurements of legs: I 3.00 (0.91, $0.40,0.74,0.61,0.34)$, II $3.28(0.94,0.42,0.89,0.63,0.40)$, III $3.01(0.93,0.40,0.65,0.71,0.32)$, IV 4.52 (1.41, 0.46, $1.08,1.08,0.49)$. Leg formula: 4231.

Palp (Figs. 5-7, 10-12): Femur and patella without apophyses. RTA not branched, wide, flat and with blunt apex; from ventral view, RTA with a ridged apophysis on the prolateral side. Embolar part strongly sclerotized, wide; EPA strong, slender and long, originating from the inner side of embolar part, transversally curved to the prolateral side. Embolus long, angled across tegular tip, stretched proximally along membranous, slightly depressed part to the middle of bulb. Tegulum significantly lower than the base of embolus; subtegulum small, visible in ventral view. Seminal duct relatively short.

Female. Body length $3.46^{-3.83}(\mathrm{n}=2)$. One paratype measured (Fig. 1): body length 3.46; carapace length 1.52, width 1.20; abdomen length 1.94, width 1.40. Eyes sizes and interdistances: AME 0.06, ALE 0.11, PME 0.09, PLE 0.10; AME-AME 0.11, AME-ALE 0.05, PME-PME 0.21, PME-PLE 0.12. MOA length 0.25 , front width 0.26 , back width 0.38. Clypeus height 0.04 . Measurements of legs: I $2.70(0.82,0.31,0.65,0.53,0.39)$, II 2.85 (0.82, 0.36, 0.72, $0.54,0.41)$, III $2.84(0.84,0.36,0.60,0.62,0.42)$, IV 4.11 $(1.22,0.47,0.91,0.99,0.52)$. Leg formula: 4231 . Carapace coloration lighter than in male, and abdomen coloration darker than in male. Other characters as in male.

Epigyne (Figs. 3-4): Posterior edge flat and wide, expanding above epigastric groove, with a strongly sclerotized hind part; the posterior part with a pair of hoods; copulatory openings close to each other. Vulva (Figs. 8-9): Copulatory ducts long, straight, almost parallel. Primary spermathecae oval, separated from each other by almost the diameter, proximally with short tubular branch; secondary spermathecae small, spherical, very close to each other; primary and secondary spermathecae connected by slender tube.

Distribution. China (Hebei).

\section{Acknowledgments}

Thanks to Mr. Jinsong Wang for his helping in the field works. This work was supported by the National Natural Science Foundation of China (No. 31372154) and the Natural Science Foundation of Hebei Province (No. C2014201041).

\section{References}

Deeleman-Reinhold, C. L. 2001. Forest spiders of South East Asia: with a revision of the sac and ground spiders (Araneae: Clubionidae, Corinnidae, Liocranidae, Gnaphosidae, Prodidomidae and Trochanteriidae). Brill, Leiden, $591 \mathrm{pp}$.

Dondale, C. D. \& Redner, J. H. 1976. A rearrangement of the North American species of Clubiona, with descriptions of two new species (Araneida: Clubionidae). Can. Entomol., 108: 1155-1165.

Dondale, C. D. \& Redner, J. H. 1982. The insects and arachnids of Canada, Part 9. The sac spiders of Canada and Alaska, Araneae: Clubionidae and Anyphaenidae. Research Branch, Agriculture Canada, Publ., 1724: 1-194.

Edwards, R. J. 1958. The spider subfamily Clubioninae of the United States, Canada and Alaska (Araneae: Clubionidae). Bull. Mus. Comp. Zool., Harvard, 118: 365-436.

Li, S. Q. \& Wang, X. P. 2015. Endemic spiders in China, version 1.0. Available from http://www.amaurobiidae.com/araneae/index. php. (accessed 22 November 2015)

Lohmander, H. 1944. Vorlaufige Spinnennotizen. Ark. Zool., 35(A, 16): $1-21$

Mikhailov, K. G. 1995. Erection of infrageneric groupings within the spider genus Clubiona Latreille, 1804 (Aranei Clubionidae): a typological approach. Arthropoda Selecta, 4(2): 33-48.

Mikhailov, K. G. 2012. Reassessment of the spider genus Clubiona (Aranei, Clubionidae). Vestn. Zool., 46: 177-180.

Simon, E. 1932. Les arachnides de France. Tome VI. Synopsis générale et catalogue des especes francaises de l'ordre des Araneae; 4e partie. Paris, 6: 773-978.

Song, D. X., Zhu, M. S., Gao, S. S. \& Guan, J. D. 1991. Six species of clubionid spiders (Araneae: Clubionidae) from China. J. Xinjiang Univ., 8: 66-72.

Wiehle, H. 1965. Die Clubiona-Arten Deutschlands, ihre naturliche Gruppierung und die Einheitlichkeit im Bau ihrer Vulva (Arach., Araneae). Senckenberg. Biol., 46: 471-505.

World Spider Catalog 2015. World Spider Catalog. Natural History Museum Bern, online at http://wsc.nmbe.ch, version 17.0, accessed on 22 November 2015.

Wunderlich, J. 2011. Extant and fossil spiders (Araneae). Beitr. Araneol., 6: 1-640.

Zhang, G. R. \& Hu, Y. J. 1991. Three new species of the spiders of the genus Clubiona from China (Araneae: Clubionidae). Acta Zootaxon. Sinica, 16: 417-423.

Received December 23, 2015 / Accepted February 15, 2016 